\title{
A SUSTENTABILIDADE E A FENOMENOLOGIA DO PERTENCER
}

\author{
Verônica Maria Bezerra Guimarães ${ }^{1}$
}

\section{RESUMO:}

Trata-se de um estudo de interdisciplinaridade na sustentabilidade, com base em ciências sociais e jurídicas, proveniente do Doutorado em Desenvolvimento Sustentável no CDS/UnB, onde se refletiu sobre modelos de sustentabilidade do povo indígena kaiowá-guarani do sul do Mato Grosso do Sul. A teoria situa-se no âmbitos da: fenomenologia, pertencimento e topofilia. Foi realizado trabalho de campo, em 2014, em três terras: Te'ýkue, Sucurui'y e Jatayvary onde adotaram-se técnicas de observação direta, conversas, depoimentos gravados e transcritos, diários de campo, caminhadas e registros fotográficos. A ideia de pertencer à terra, vivenciada pelos kaiowá-guarani, revela uma importante contribuição a "ciência da sustentabilidade".

Palavras-chave: sustentabilidade; fenomenologia; pertencimento; topofilia; kaiowá-guarani Title:

\section{SUSTAINABILITY AND THE PHENOMENOLOGY OF BELONGING}

\section{SUMMARY:}

It is an interdisciplinary study on sustainability, based on social and legal sciences, from the $\mathrm{PhD}$ in Sustainable Development at CDS / UnB, where it was reflected on sustainability models of the Kaiowá-Guarani indigenous people of southern Mato Grosso do Sul. The theory lies in the fields of phenomenology, belonging and topophilia. Fieldwork was carried out in 2014 on three lands: Te'ykue, Sucurui'y and Jatayvary where techniques of direct observation, conversations, recorded and transcribed testimonies, field diaries, hiking and photographic records were adopted. The idea of belonging to the land, experienced by the Kaiowá-Guarani, reveals an important contribution to the "science of sustainability".

Keywords: sustainability; phenomenology; belonging; topophilia; kaiowá-guarani

\section{Introdução}

O presente trabalho está situado nos estudos de interdisciplinaridade na sustentabilidade, com uma base em ciências sociais e jurídicas e, decorre das pesquisas realizadas no Doutorado em Desenvolvimento Sustentável no CDS/UnB. A pesquisa propiciou a oportunidade de refletir sobre modelos de sustentabilidade a partir de concepções de um povo, os kaiowá-guarani do sul do Mato Grosso do Sul, que independentemente do rótulo de sustentável, adota um modelo de vida, em que os séculos de colonização não foram

\footnotetext{
${ }^{1}$ Mestre em Direito Público pela UFPE. Doutora em Desenvolvimento Sustentável pela UnB. Professora Adjunta na UFGD.
} 
capazes de subjugá-lo totalmente. Modelo este que, junto com o de outros povos tradicionais, inspira e alimenta concepções das mais belas teorias ecológicas. Aliás, para eles, terra e meio ambiente faz parte de um todo, sem dicotomias, frações ou subdivisões pseudo-didáticas. Terra, natureza e saberes para uma vida em harmonia, respeito e cuidado entre os seres constitui a essência do seu modo de ser.

As reflexões teóricas situam-se no campo filosófico da fenomenologia, do pertencimento e da topofilia. Para o trabalho de campo, realizado em 2014, em três terras: Te'ýkue, Sucurui'y e Jatayvary foram adotadas técnicas de observação direta, conversas, depoimentos gravados e transcritos, diários de campo, caminhadas, registro de fotografia e participação em encontros de professores indígenas.

A contribuição do modelo kaiowá-guarani de proteção da terra traz consigo a dimensão do sagrado, da reverência, do respeito aos ciclos de vida e de recuperação da natureza, do pertencimento e da ligação com a terra e com os seres que a habitam. Os seres e os saberes numa ideia de complementariedade. Da terra que produz o alimento e o modo de ser. Modo de ser baseado na oralidade, nas histórias que são perpassadas pelas gerações, pela fala mansa, doce e metafórica.

Os kaiowá, ka’aguygua ou ka’aygua, literalmente, os da mata ou povo da mata são tradicionalmente povos agricultores, possuidores de uma forte identidade territorial. A cosmologia e o conhecimento guarani-kaiowá possuem uma dimensão do sagrado sobre a terra e os seres que a habitam. Os mitos são vivenciados na realidade de acordo com seu modo de ser.

Mesmo diante de séculos de colonização com seus ciclos econômicos destrutivos, as terras indígenas Guarani-Kaiowá guardam respostas inspiradoras para a ideia de sustentabilidade. E revelam uma riqueza de sociobiodiversidade que não há no entorno. Seu modo de ser pode contribuir para a teoria ecológica, para a sociobiodiversidade, de modo a promover transformações na sociedade, na economia e no meio ambiente envolvente.

A sociedade atual é desenraizada, sem topofilia. Diferentemente dos kaiowá-guarani em que terra e vida compõem uma comunidade de origem terrestre, de natureza humana e de destino planetário. Há uma simplicidade na complexidade, onde esta constitui uma religação com os sistemas integrados do universo. O sistema vida guarani-kaiowá, com sua dimensão espiritual, poética e telúrica da sustentabilidade da terra, representam o que poderia ter sido e o que ainda pode ser: a sabedoria para uma vida melhor. 
A ideia de pertencer à terra, vivenciada pelo kaiowá-guarani, revela uma importante contribuição a "ciência da sustentabilidade". Isto porque, podem ser ricas as interações interdisciplinares entre saberes científicos e saberes tradicionais no campo da sustentabilidade, pois, podem operar de modo dialógico ao se pensar e propor soluções para problemas complexos cuja origem vem de processos colonizadores. Além disso, o foco da sustentabilidade pode se deslocar da ideia de gestão ou gerenciamento ambiental e territorial para novos modelos de ser e estar na terra. Pertencendo à terra e convivendo na, pela e com a terra, bem como com todas as suas espécies.

A sabedoria kaiowá-guarani revela que a gente que pertence à terra e não a terra que nos pertence. Isto mostra uma lógica diferente de se relacionar com a terra, bem distante de racionalidades guiadas por processos de apropriação, de dominação e de destruição. Pertencer é amar, é envolver-se, é sentir-se parte de. É um elemento propulsionador para a construção de realidades integrativas entre natureza e sociedade. Existe a percepção da terra como um ser vivo que tem corpo, alma e palavra. E são as doces palavras e atitudes que se equilibram com essa terra. O conhecimento dos mais velhos, dos mestres tradicionais e dos guardiões da natureza reforça esse modo de pertencer.

Sustentabilidade com pertencimento implica em abandonar discursos economicistas, burocratizados e dominadores. E, também, em abdicar conceitos apropriados por diversos setores econômicos que enxergam a sustentabilidade como uma tendência de mercado, como algo bom para o marketing das suas empresas, podendo agregar valor aos seus produtos.

A cultura da terra dos kaiowá-guarani tem muito a contribuir para a construção de uma "sustentabilidade" regional. Suas bases culturais do uso da terra, a partir de uma visão de mundo/cosmologia endógena, genuína, diversificada, com inserção de saberes locais, de gente que mexe com a terra poderia vitalizar o assim, o degastado, banalizado, vazio, institucionalizado e normatizado "slogan" do desenvolvimento sustentável.

A ideia de sustentabilidade da e pela vida (pelo modo de ser e conviver com e na natureza) está ligada aos sentimentos e ao conhecimento ligado a terra para e por uma vida melhor. Uma vida mais amorosa. Para algo que alimente a alma com base em comportamentos que estejam calcados em uma ética do respeito e do cuidado com a terra. Nesta perspectiva, o ser humano deve ser colocado em um lugar que se comporte como mais uma das espécies do planeta. Onde a sua suposta superioridade humana seja trabalhada em favor de modos de vida diversos: humanos e não-humanos. Possibilitando, assim, um 
compartilhamento e expansão com as demais formas de vida. A sustentabilidade e diversidade da vida do modelo kaiowá-guarani de proteção da terra traz consigo a dimensão do sagrado, da reverência, do respeito aos ciclos de vida e de recuperação da natureza, do pertencimento e da ligação com a terra, que passa pelos seres que a habitam.

\section{A fenomenologia do pertencer}

O caminho analítico adotado neste trabalho é o de que a noção de pertencimento, calcado na filosofia da fenomenologia e da percepção, conduz a sustentabilidade da vida, esta baseada em fortes vínculos entre o humano e a Terra.

Inicialmente, a percepção como "objeto científico" teve seu desenrolar a partir de estudos no campo da fisiologia e da psicologia. Mas foi na fenomenologia que encontrou um campo fecundo para pesquisas e investigações. Como aponta Escobar (2011, p. 59):

Como filosofia de la experiencia, el objeto de estudio de la fenomenología es el seren-el mundo, es decir, antes de que los fenómenos sean capturados por el pensamiento y sin su reducción a cualquier verdad o esencia transcendental. En lugar de intentar dar con una visión objetiva de la realidad, la fenomenología comienza con la hipótesis de que el mundo es primero y después conocido, y que es mundo-vida (como dominio de la existencia social cotidiana y la actividad práctica), más que una visión del mundo, lo que cuenta en la explicación de la forma en que el mundo se nos presenta. De este modo, la fenomenología prioriza la experiencia vivida por encima de los conocimientos teóricos, considera diversos tipos de conocimientos en pie de igualdad y reconoce que el sujeto siempre está implicado en el mundo y en el conocimiento mismo.

O pertencer passa pelo perceber, conceito que envolve ideia, sentidos e sentimentos. Para Aristóteles (385-322 a. C.), a percepção percorre os sentidos: visão, audição, olfato, paladar e tato. A percepção sensível está articulada aos objetos sensíveis e as partes do corpo capazes de percebê-los. É uma operação dinâmica articulada que não precisaria recorrer ao pensamento: "os sentidos podem, inclusive, perceber que percebem” (SAES, 2010, 11-4).

Para alguns filósofos modernos, a percepção é uma representação de pensamentos e ideias, neste sentido, passa por processos racionais. Em Descartes (1596-1650), a percepção é um ato intelectual. Em Hume (1711-1776) a percepção é ampliada em duas categorias: impressões, que são mais fortes e vividas e pensamentos ou ideias, que são percepções mais tênues. São gradações interdependentes, pois, "as ideias dependem das impressões para existir" (SAES, 2010, p. 20).

Na filosofia de Kant (1724-1804): "as coisas que existem na realidade e que podem ser objetos da nossa experiência somente aparecem para nós como fenômenos, nunca como 
coisas-em-si. Assim, o que podemos legitimamente perceber são fenômenos" (SAES, 2010, p. 23). A percepção pelos fenômenos se dá pela consciência das sensações que são apreendidas pela intuição empírica de um objeto representado como real no tempo e espaço (SAES, 2010, 25).

Os estudos mais contemporâneos sobre percepção encontraram na fenomenologia um campo fecundo de reflexões e de desenvolvimento. Para Cerbone $(2013$, p.13) que estudou os principais filósofos da fenomenologia - Husserl, Heidegger, Sartre e Merleau-Ponty - a palavra fenomenologia significa: "o estudo dos fenômenos, onde a noção de um fenômeno e a noção de experiência, de um modo geral, coincidem. Portanto, prestar atenção à experiência em vez de àquilo que é experienciado é prestar atenção aos fenômenos".

Apesar dos autores acima citados serem identificados como fenomenólogos, cada um deles deixou uma marca própria na filosofia dos fenômenos. Serão discutidas algumas ideias de Maurice Merleau-Ponty (1908-1961), em seu livro Fenomenologia da Percepção pelo fato do autor ser uma das bases teóricas de Tim Ingold um dos autores aqui adotado por analisar a percepção ambiental.

Merleau-Ponty parte de uma crítica de posições dualistas como mente-corpo e sujeitoobjeto. Para Merleau-Ponty (1999, p. 1-2) a fenomenologia é "o estudo das essências", de todas elas: essência da percepção, da consciência... Mas também: "uma filosofia que repõe as essências na existência". É transcendental e ao mesmo tempo "um relato do espaço, do tempo, do mundo "vivido"". O autor rompe com o causalismo, o empirismo e o intelectualismo moderno, pois, para ele a fenomenologia: "é a tentativa de uma descrição direta de nossa experiência tal como ela é, e sem nenhuma deferência à sua gênese psicológica e às explicações causais que o cientista, o historiador ou o sociólogo dela possam fornecer".

“O mundo é aquilo que nós percebemos”. Mas também, “o mundo é não aquilo que eu penso, mas aquilo que eu vivo; eu estou aberto ao mundo, comunico-me indubitavelmente com ele, mas não o possuo, ele é inesgotável” (MERLEAU-PONTY, 1999, p.14). Ele constrói sua teoria da percepção de base fenomenológica a partir de críticas ao empirismo ${ }^{2}$ e ao intelectualimo ${ }^{3}$, que ele chama de prejuízos clássicos. A partir daí propõe a ideia de retornar aos fenômenos, redespertando e redescobrindo a experiência perceptual. O autor

\footnotetext{
${ }^{2}$ Segundo Cerbone (2013, p. 173): “a descrição empirista da percepção, como recepção de estímulos e posse de sensações, converte a experiência em algo completamente passivo e inerte: uma série de eventos que surgem de um modo causal, quase mecânico. (...) Na verdade, o empirismo parece negligenciar inteiramente o fato de que a experiência perceptual é vivida por alguém que percebe. Nas palavras de Merleau-Ponty (1999, p.26): "construímos a percepção com o percebido".

${ }^{3} \mathrm{O}$ intelectualismo trata a percepção como um ato mental do juízo. Segundo Merleau-Ponty (1999, p.60): "o intelectualismo vive da refutação do empirismo e nele o juízo tem frequentemente a função de anular a dispersão possível das sensações".
} 
procura restituir a percepção no seu sentido originário. Esta operação passa pela corporificação da própria experiência do ser. A nossa existência está interconectada a consciência, a corporificação e ao mundo manifesto através de nossa experiência perceptiva:

A vida da consciência - vida cognoscente, vida do desejo ou vida perceptiva - é sustentada por um "arco intencional" que projeta em torno de nós nosso passado, nosso futuro, nosso meio humano, nossa situação física, nossa situação ideológica, nossa situação moral, ou antes que faz com que estejamos situados sob todos esses aspectos. É este arco intencional que faz a unidade entre os sentidos, a unidade entre os sentidos e a inteligência, a unidade entre a sensibilidade e a motricidade (MERLEAU-PONTY, 1999, p.190).

Tim Ingold (2000, p. 168-71) ao revisitar a fenomenologia de Merleau-Ponty coloca em perspectiva as superações das dicotomias entre biologia e cultura; mente e corpo, pois, para ele, isso tudo faz parte do mesmo processo de pensar, de perceber, de lembrar e de aprender no contexto ecológico das interrelações das pessoas com seu meio ambiente.

Ingold (2000, p. 139) ao analisar a relação entre a terra e a memória ${ }^{4}$, concebe a terra como um campo de moradia para seres de todo tipo: humanos e não-humanos geneticamente inspirados por uma concepção de diversidade biocultural. Habitar a terra é constituir um lugar como um locus de crescimento pessoal e de desenvolvimento em que cada lugar forma o centro de uma esfera de nutrição (INGOLD, 2000, p. 149). Neste modelo relacional, Ingold concorda com a ideia de J. Leach, em que "parentesco é geografia", então "as vidas das pessoas e a história das suas relações podem ser traçadas nas texturas da terra" (INGOLD, 2000, p. 150). Nesta perspectiva, as relações das pessoas derivam da sua identidade e pertencimento à terra, elementos que caracterizam os povos indígenas e podem servir de inspiração:

Indigenous people regard all products of the human mind and heart as interrelated, and as folowing from the same source: the relationships between the people and their land, their kinship with the other living creatures that share the land, and with the spirit world. Since the ultimate source of knowledge and creativity is the land itself, all of the art and science of a specific people are manifestations of the same underlying relationships, and can be considered as manifestations of the people as a whole (INGOLD, 2000, p. 150).

A percepção do meio ambiente também é uma construção cultural da natureza. Sobre o conceito de meio ambiente, Ingold (2000, p. 20) tem a seguinte posição: 1) meio ambiente é um termo relativo. Não pode existir um organismo sem meio ambiente, nem meio ambiente sem organismo. Seria algo como: eu sou o meio ambiente, o meio ambiente sou eu; 2) o meio

\footnotetext{
4 "Land and history, in short, figure as mutually exclusive alternatives. For indigenous people themselves, by contrast, it is in their relationships with the land, in the very business of dwelling, that their history unfolds. Both the land and the living beings who inhabit it are caught up in the same, ongoing historical process" (INGOLD, 2000, p. 139).
} 
ambiente nunca está completo, está sempre em construção; 3) não se deve confundir o meio ambiente com a natureza.

Steil e Carvalho (2012, p. 11) em obra que analisa a dimensão ecológica no pensamento de Ingold situam o seu pensamento sobre o ser humano como o de: "um ser imerso no fluxo da vida e dependente dos processos e movimentos dos materiais que constituem nossos corpos e nossas mentes, com os quais traçamos as linhas de nossa história natural e cultural". Para os autores, nesta interpretação, Ingold:

\begin{abstract}
leva a sério o pertencimento de todos os seres que habitam o mundo à trama da vida, ele retira o caráter de externalidade dos seres humanos em relação ao mundo, ao mesmo tempo em que o apresenta como um ser menos potente para controlar os destinos do planeta e mais partícipe das linhas de vida que o atravessam, constituem e ultrapassam (STEIL, CARVALHO, 2012, p. 11).
\end{abstract}

A prática do oguatá dos kaiowá-guarani simboliza uma percepção através do movimento do caminhar. Como coloca Ingold ${ }^{5}$ (2011), o mundo é percebido através dos pés e a locomoção é a porta de entrada para a nossa percepção do mundo. Ele argumenta que a noção de espaço é abstrata, vazia e distante da realidade da vida e da experiência. Enquanto que a ideia de lugar é definida pelo movimento onde as pessoas habitam. Ao refletir sobre um trabalho de campo do povo Evenki na Sibéria ${ }^{6}$ acerca da localização das suas terras originais por David Anderson, constatou-se que no passado as pessoas viajavam e viviam não em qualquer lugar, mas em todo lugar. Contudo esse "todo lugar" não é "lugar nenhum". Eles habitavam a terra ao longo de caminhos que os conduziam de um lugar a outro lugar através do movimento. Esta análise parece ser bastante esclarecedora e se aproxima da filosofia do caminhar, da andança, do oguatá dos kaiowá-guarani.

Esta reflexão sobre o "lugar" e suas inúmeras possibilidades de percepções, inclusive como algo ideal construído coletivamente por uma cultura faz pensar no profetismo tupiguarani da Terra sem Mal, que nas palavras de Clastres (2007, p. 38) é um lugar "privilegiado, indestrutível, em que a terra produz por si mesma os seus frutos e não há morte", situado às vezes a leste, outras a oeste, para onde iriam as almas dos mortos, mas também, os vivos. Danças, festas e bebidas seriam as regras existentes em um lugar

\footnotetext{
5 "But if perception is thus a function of movement, then what we perceive must, at least in part, depend on how we move. Locomotion, not cognition, must be the starting point for the study of perceptual activity. Or more strictly, cognition should not be set off from locomotion, along the lines of a division between head and heels, since walking is itself a form of circumambulatory knowing" (INGOLD, 2011, p. 46).

6 "Evenki herders did not formerly live in space rather than place. The illusion that they did is a product of our own cartographic conventions that lead us to imagine the surface of the earth divided into a mosaic of areas, each occupied by a named nation or ethnic group. On a map drawn according to these conventions, the few thousand Evenki appear to occupy an area almost twice the size of Europe! The Evenki people, however, did not occupy their country, they inhabited it. And whereas occupation is areal, habitation is lineal" (INGOLD, 2011, p. 149).
} 
inicialmente descrito como de abundância: "o milho cresce sozinho, as flechas alcançam espontaneamente a caça...Opulência e lazeres infinitos" (Idem, p. 85).

O lugar constitue os territórios existenciais, vistos como uma "construcción eco-cultural del território-región" (ESCOBAR, 1999, p. 271). Neste sentido, "o lugar é central no tema do desenvolvimento, da cultura e do meio ambiente, e é igualmente essencial, por outro lado, para imaginar outros contextos, para pensar acerca da construção da política, do conhecimento e da identidade" (ESCOBAR, 2005, p. 11).

\section{Sustentabilidade e pertencimento}

A fenomenologia de pertencimento a um lugar se relaciona com o que o geógrafo humanista Yi-Fu Tuan, em sua obra seminal chama de topofilia, ou seja, "o elo afetivo entre a pessoa e o lugar ou ambiente físico" (TUAN, 2012, p. 19). Os laços afetivos do ser humano para com o meio ambiente podem se expressar de diferentes formas: estética, tátil ou sentimentalmente. A primeira pode ser sentida, por exemplo, através da beleza paisagística de um determinado lugar, como uma praia, uma montanha ou uma floresta. Revela o prazer em se estar em um lugar que desperta ou evoca sensações de prazer estético.

O contato físico ou tátil apresenta muitas nuances, mas uma delas pode ser descrita pelo contato profundo com a terra. Tuan cita a relação do trabalhador rural com a natureza, em que esta formaria parte dele, o personificando. Para o autor: "esse sentimento de fusão com a natureza não é simples metáfora. Os músculos e as cicatrizes testemunham a intimidade física, da dependência material e do fato de que a terra é um repositório de lembranças e mantém a esperança" (TUAN, 2012, p. 141). O que não significa dizer que devido a esta proximidade ou personificação não ocorram sentimentos ambivalentes como os de amor e ódio a depender das condições ambientais existentes no espaço e no tempo.

Já os sentimentos associados com o lugar podem gerar imagens e estímulos sensoriais potencialmente infinitos. Para Tuan (2012, p. 161): "aquilo em que decidimos prestar atenção (valorizar ou amar) é um acidente do temperamento individual, do propósito e das forças culturais que atuam em determinada época". Há lugares que despertam "sentimentos topofílicos". Para o autor: "o meio ambiente pode não ser a causa direta da topofilia, mas oferece o estímulo sensorial que, ao agir como imagem percebida, dá forma às nossas alegrias e ideais" (Idem). 
Para Eric Dardel, na sua também geografia humanista, há uma reflexão sobre a ligação do homem com a Terra em uma perspectiva mítica. Para o autor, a Terra é: origem, nutrição, regeneração e fonte de vida, onde: "vir ao mundo é se destacar da terra, mas sem romper jamais, inteiramente, com o cordão umbilical pelo qual a terra nutre o homem" (DARDEL, 2015, p. 48). A origem mítica da Terra é uma presença contínua, em que:

o mito não é de forma alguma a narrativa de um acontecimento ocorrido em uma data precisa e única. Ele é absoluto, isento do tempo como data ou momento. Essencial, ele engloba todos os existentes. Essa "essência", realidade típica e exemplar, os diversos seres a atualizam, a repetem e a manifestam (Idem, p. 51).

Dardel afirma o poder telúrico da terra que não se limita a superfície visível das coisas. Há um lado da terra que está sempre pronto a se manifestar: a dimensão do sagrado, que caminha junto com a estética e a capacidade de contemplação. Para o autor: "habitar a Terra, percorrê-la, plantar ou construir é tratá-la como um poder que deve ser honrado: cada um de seus atos é uma celebração, um reconhecimento do laço sagrado que une o homem aos seres da Terra, das águas ou do ar” (Idem, p. 54).

No sentido etimológico, a Terra deve ser "contemplada". Consequentemente, geografia e cosmologia seriam a mesma coisa. Dardel é enfático: "nenhum fato pode refutar jamais a interpretação mítica, porque só o que é garantido pelo mito se torna verdadeiramente real" (Idem, p. 54). A realidade do mito é vivida pelos sujeitos coletivamente através da vida diária e fortalecida em alguns momentos, como cerimônias e festas. Dardel coloca que a geografia não pode afastar-se do mito, pois, "o mito, sempre colocado sobre as coisas, para as fundar, é precisamente o que faz a realidade aparecer como realidade, e a realidade confirma a todo momento o "fundamento" mítico" (Idem, p. 65).

Mitos e memórias através das paisagens constituídas por árvores, águas e rochas no ocidente compõem o livro de história e arte ambiental de Schama (1996), onde considera que os velhos mitos da natureza nunca desapareceram, embora nem todas as culturas abracem a natureza com igual ardor e possuam suas fases de maior e menor entusiasmo. $\mathrm{O}$ autor reconhece a importância da complexidade de mitos, metáforas e alegorias da natureza para a constituição da memória em um mundo movido a máquinas, cuja inventividade constitui nossa tragédia, uma vez que o domínio da natureza parece ser nossa marca registrada, podendo levar a nossa destruição (Idem, p. 24-5). 
O sentido de pertencimento a um lugar constitui um elemento importante para a construção do movimento de ecocrítica ${ }^{7}$ na literatura, como mostra Heffes (2013) ao percorrer diversos textos e representações artísticas do que ela chama de "políticas da destruição e poéticas da preservação" do meio ambiente na América Latina. O pertencimento mostra a nossa relação com um lugar específico, determinando nossas formas de ser e atuar que está representada de diversas formas na literatura (Idem, p. 29).

Speller (2005, p. 133) faz uma ampla revisão de literatura sobre o tema da vinculação da pessoa ao lugar com base em processos cognitivos, afetivos e comportamentais. Sua argumentação se baseia em três conceitos centrais: a) identidade de lugar; b) vinculação ao lugar e c) tempo e lugar. A ideia de lugar tem sido trabalhada por diferentes perspectivas desde muito tempo. Aristóteles já invocava o lugar através de uma dimensão proveniente da relação entre a pessoa e o ambiente físico pelos sentimentos de pertença.

A construção da identidade de lugar é um processo dinâmico que pode ser percebido através dos espaços de pertencimento e de vivência cujos vínculos cognitivos e emocionais traduzem significados para indivíduos ou grupos sociais. Neste sentido, poderia dizer que a identidade étnica se relaciona com a identidade de lugar. Como pontuam Mourão e Cavalcante (2011, p. 212), “a função primária do lugar é a de gerar um senso de pertencimento e de conexão".

Para Elali e Feijó de Medeiros (2011, p. 55), a vinculação ao lugar possui muitas dimensões, dentre as quais se destacam: a dimensão funcional, que se refere ao papel desempenhado pelo espaço físico; a dimensão simbólica, em que a memória de lugares experenciados constitui uma fonte importante de estudos e a dimensão relacional, referente às interações entre pessoas e espaços.

A vinculação ao lugar pode estar associada ao que Escobar (1999) chama de defesa do lugar. A defesa é feita pelos povos para a manutenção do seu modo de se relacionar com a natureza/cultura. $\mathrm{O}$ autor, ao analisar a defesa do lugar, realizada pelos movimentos sociais com ênfase na população das florestas tropicais, verificou que esta se baseia em quatro direitos fundamentais: a identidade, o território, a autonomia política e a visão própria de desenvolvimento" (ESCOBAR, 2005, p. 12-3).

\footnotetext{
7 "La ecocrítica consiste en el estudio de la literatura y el medio ambiente a través de un espíritu de compromiso con la práctica ambiental". O temo foi possivelmente cunhado em 1978 por William Rueckert em um ensaio chamado "Literature and Ecology: an experiment in ecocriticism". (HEFFES, 2013, p. 29-30).
} 
O tempo é um elemento imprescindível para a constituição de lugares, com seus vínculos, afetos e significados e, de experiências ambientais. A memória reforça positiva ou negativamente as lembranças vividas em um lugar. De modo que o passado ambiental de indivíduos ou grupos contribui para a constituição da vinculação ao lugar.

O lugar pode possui um viés individual e/ou coletivo que perpassa uma linha do tempo entre passado, presente e futuro. E, dependendo da formação e orientação do pesquisador, são destacados elementos físicos, sociais, culturais, comportamentais, espirituais, telúricos, poéticos, dentre outros, relativos ao lugar. Um lugar também pode ser o que Tuan (2013, p. 240) chamou de "uma pausa no tempo", baseado em aportes da fenomenologia e do existencialismo, para situar a experiência humana com o lugar. Os pontos principais do seu pensamento são:

\begin{abstract}
Se o tempo for concebido como fluxo ou movimento, então lugar é pausa. De acordo com esse enfoque, o tempo humano está marcado por etapas, assim como o movimento do homem no espaço está marcado por pausas. Do mesmo modo como o tempo pode ser representado por uma flecha, uma órbita circular ou caminho de um pêndulo oscilante, assim também os movimentos no espaço; e cada representação tem seu conjunto característico de pausas ou lugares. 2) Leva-se tempo para se sentir afeição por um lugar, a qualidade e a intensidade da experiência é mais importante do que a simples duração. 3) Estar arraigado em um lugar é uma experiência diferente da de ter e cultivar um "sentido de lugar".
\end{abstract}

Experienciar um lugar passa pelo racional, mas também pelos sentidos (tato, paladar, olfato, audição e visão) e pelos sentimentos. Metáforas, gestos e falas kaiowá como: "comer a terra", "terra não me pertence, eu é que pertenço a terra", "eu sou a terra", "a cor da terra é a cor da pele" revelam muito do pertencer à terra. Há um sentimento étnico coletivo de pertencer à terra que perpassa a flecha do tempo. Pertencer à terra é diferente de dominar, ter ou apropriar-se da terra.

A ideia de sacralidade e de pertencimento à terra aparece no famoso discurso de Seattle, cacique dos Duwamish, em 1856, como resposta ao então governador do território de Washington, Isaac Stevens, sobre o seu intuito de comprar a terra dos indígenas. A íntegra do discurso pode ser encontrada em Boff (1999, p. 335-41), do qual serão destacados alguns trechos que se relacionam mais diretamente com os temas aqui tratados. O cacique questiona: “Como podes comprar ou vender o céu e o calor da Terra?" Ele contrapõe a ideia do branco, que não compreende o modo de viver dos Duwamish, ressaltando a sacralidade da natureza: "Cada torrão desta terra é sagrado para o meu povo". A interdependência de todos os seres está evidente nesta passagem: "Se todos os animais se acabassem, o homem morreria de 
solidão de espírito. Porque tudo o que acontece aos animais, logo acontece também ao homem. Tudo está relacionado entre si”. E sobre o forte vínculo de pertencimento:

De uma coisa sabemos: a Terra não pertence ao homem. É o homem que pertence à Terra. Disto temos certeza. Todas as coisas estão interligadas como o sangue que une uma família. Tudo está relacionado entre si. O que fere a Terra fere também os filhos e filhas da Terra. Não foi o homem que teceu a trama da vida: ele é meramente um fio da mesma. Tudo o que fizer à trama, a si mesmo fará (BOFF, 1999, p.339).

A Terra tem uma dimensão material e terrenal da existência em que pertencemos a ela, viemos dela e somos ela. Pertencer a terra é senti-la e conhecê-la como unidade, no sentido de que o homem é mais um dos seres que habita a terra e não o seu dominador. Pertencer é ser e não ter, a ideia de que não é a terra que pertence ao homem e sim o homem à terra se aproxima mais das éticas não-antropocêntricas. Ser Terra significa que: "temos elementosTerra no corpo, no sangue, no coração, na mente e no espírito" (BOFF, 2012, p. 85).

A relação de pertença é ontológica, existencial e recíproca. Por isso, a transformação da terra e dos seus "recursos" em mercadorias é incompatível com o vínculo de pertencimento étnico, que é passado de geração em geração pela oralidade como principal sistema de aprendizagem e de sensibilidades. Pertencer a uma terra por nascimento ou opção possui vários sentidos individual e coletivo de ordem: social, política, econômica, espiritual... Mas, "a relação de pertença resultante pode ser caracterizada como uma relação de intimidade ou de inerência. A terra está envolvida na constituição de um povo. Caracteriza-o, tal como ele a caracteriza" (WHITT, 2003, p. 21). A terra é o local do conhecimento. Conforme Whitt, 2003, p. 29:

\footnotetext{
Narrar histórias é uma forma de conversação com o mundo natural, parte da maneira como as coisas chegam a ser conhecidas. Transmite importantes informações sobre a natureza desse mundo, dos seus seres e dos seus processos. As histórias são um meio de relacionar conhecimento e de correlacionar comportamentos. Mostram como "os do passado" estão ligados à terra, aos do presente e aos "ainda não nascidos", e como os do presente se devem comportar à luz destes factos.
}

A relação de pertença é reafirmada pelos laços genealógicos, gerando vínculos de filiação e morais entre gerações. "Como tal, ela persiste, não cessa como resultado de "remoções" nem termina com a morte. Os seres individuais estão situados no interior de uma família, no interior de uma geração e no interior de uma terra cheia de outros seres, humanos e não humanos" (Idem, p. 22).

Pertencer é não estar preso. É ter liberdade para desenvolver potencialidades em perspectiva individual e coletiva em um lugar. O que para os kaiowá-guarani, em condições ideais, se revelaria pela mobilidade de habitar, de praticar agricultura, de caminhar, de viver 
conforme a tradição, no teko, no modo de ser através dos vínculos afetivos e espirituais com a terra.

Pertencer à terra também implica em responsabilidades e cuidados na sua conservação. “Cortar esses vínculos é cortar o conhecimento neles embebido e abandonar o seu papel no desempenho das responsabilidades que cada um tem como guardião dessa porção do mundo natural. É alienar, se não for destruir, todo um sistema de conhecimento e de valores" (Idem, p. 30).

Devido ao forte vínculo de pertença, por mais destruído que se encontre um lugar as pessoas a ela vinculadas não cortam a sua ligação com ela. São precisas as palavras de Whitt (2003, p. 25): "Por mais profanado que esteja um lugar, as responsabilidades de custódia do povo permanecem. Não importa quanto possa estar estragada, a terra conserva o seu poder e o seu significado". O importante nessa relação de pertencimento é que sejam mantidos seus guardiões, pois, "o estado de uma terra que perdeu os seus guardiões, e de um povo que perdeu a sua terra, são comparáveis: abandono e desterro" (Idem, p. 25).

\section{Conclusões}

São muitos os caminhos das percepções, são muitos os territórios ambientais e são muitos os kaiowá-guarani. São plurais e são únicos. Assim como foram as percepções sobre as suas percepções com a territorialidade. Percepções que foram além do pensamento racional e transitaram por aspectos fenomenológicos de sentidos e sentimentos. Eles não são sujeitos de uma dada etnia analisados de uma forma genérica. São sujeitos que embora pertençam a um grupo étnico, social, econômico, cultural, geracional e de gênero têm suas percepções individualizadas.

As percepções são importantes para a compreensão dos fluxos de vida e para a dinâmica dos territórios. Podem, inclusive, auxiliar na construção de políticas públicas que levem em consideração a diversidade de saberes e a autonomia dos povos. Para além dos encaminhamentos pragmáticos, desvendar percepções da terra e de sua gente revela toda uma riqueza e sabedoria que foi e continua sendo, em grande medida, subjugada pela prevalência de pensamentos e ações monoculturais.

A construção da sustentabilidade e as soluções de "problemas ambientais" passa pelo diálogo de saberes indígenas e de saberes não-indígenas para que juntos possam apontar 
caminhos para as questões introduzidas pelas heranças coloniais nos espaços de ocupação tradicional e nas áreas demarcadas.

O diálogo de saberes na diversidade da vida revela a importância da interculturalidade para a construção de uma sustentabilidade voltada para a recomposição da vida e para a minoração de processos de colonização que resultaram em profundas transformações culturais e ambientais. Um dos inúmeros desafios para se alcançar a sustentabilidade em bases interculturais seria harmonizar os conhecimentos étnicos com conhecimentos não indígenas paras as práticas de recuperação da terra e de manejo ambiental.

Os kaiowá-guarani têm muito a ensinar na construção de uma sustentabilidade baseada na simples e profunda noção de pertencer. Contribuições, estas, que incorporam uma dimensão espiritual na formulação de uma sustentabilidade da e pela vida que passa pelo pertencimento da sociedade a um dado território para estimular e promover mudanças. $\mathrm{O}$ que implica em viver a sustentabilidade na diversidade de saberes, dialogando sobre a construção de consensos para intervenções práticas que digam respeito aos usos naturais e culturais de uma determinada terra e gente.

O pertencer à terra perpassa a memória dos antepassados e memória da terra e dialoga com a espiritualidade, onde a terra é vista como unidade. A identidade territorial e cultural está relacionada com suas memórias individuais e coletivas; as atribuições dos nomes dos lugares a que se referem; a alimentação; as plantas e os animais sagrados; sua agricultura; seus rituais e a reverência à natureza. A emblemática frase: "a gente que pertence à terra e não a terra que nos pertence", revela também, na situação atual do kaiowá-guarani, que o pertencimento perpassa o processo de luta das terras tradicionais.

As práticas desenvolvidas pelos kaiowá-guarani históricos pareciam ser dotadas do que enquadraríamos como sustentáveis: disposição geográfica das famílias com pequenos núcleos de adensamento populacional; economia da reciprocidade; baixo consumo; consumo para o imediato, com baixa acumulação de coisas; agricultura de coivara; respeito à recuperação do solo, com o repouso dos cultivares; reverência aos seres/donos da natureza: bichos e plantas, através de rezas; diversos conhecimentos dos ciclos da terra e dos seus elementos com uma visão de integralidade e interdependência da terra.

As condições socioeconômicas e ambientais mudaram muito no decorrer de mais de um século de colonização, mas mesmo com as transformações provocadas por estes processos, há 
uma memória coletiva do que foi e do que de certa forma continua sendo a terra. Há um pertencimento e uma localização desse modo de vida. A forte tradição da oralidade kaiowáguarani traz uma contribuição mística da palavra. Uma concepção de mundo no sentido de amor a terra, de viver na natureza e com a natureza, de viver no mato e com o mato.

As práticas ditas sustentáveis também se transformaram. Mas são nessas terras, onde, com toda a herança de diversos processos de destruição do meio ambiente, ainda se encontra pulsante uma gama de conhecimentos sobre uma natureza que não foi esquecida e que pode ser recuperada, não na sua originalidade, mas através de espécies que podem repovoar esse ambiente com a ajuda das rezas e de conhecimentos que captem a riqueza da cultura kaiowáguarani.

\section{REFERÊNCIAS}

BOFF, Leonardo. Ecologia grito da terra, grito dos pobres. São Paulo: Ática, 1999. 2012 .

Saber cuidar: ética do humano, compaixão pela terra. 18. ed. Petrópolis: Vozes:

CERBONE, David R. Fenomenologia. 2. ed. Petrópolis: Vozes, 2013.

CLASTRES, Hélène. Terra sem mal. Corumbiara: Tapé, 2007.

DARDEL, Eric. O homem e a terra: natureza da realidade geográfica. São Paulo: Perspectiva, 2015.

ELALI, Gleice Azambuja, FEIJÓ DE MEDEIROS, Samia Thaís. Apego ao lugar (vínculo com o lugar - place attachment). In: CAVALCANTE, Sylvia, ELALI, Gleice A. (orgs.). Temas básicos em Psicologia Ambiental. Petrópolis: Vozes, 2011.

ESCOBAR, Arturo. El final del salvaje: naturaleza, cultura y política en la antropologia contemporânea. Santa Fé de Bogotá: CEREC, 1999.

O lugar da natureza e a natureza do lugar: globalização ou pós-desenvolvimento? In: LANDER, Edgardo (org.). A colonialidade do saber: eurocentrismo e ciências sociais. Perspectivas latino-americanas. Buenos Aires: Colección Sur Sur, CLACSO, 2005.

- Epistemologías de la naturaleza y colonialidad de la naturaleza. Variedades de realismo y constructivismo. In: MARTÍNEZ, Leonardo Montenegro (ed.). Cultura y Naturaleza. Bogotá: Jardín Botánico de Bogotá, José Celestino Mutis, 2011.

HEFFES, Gisela. Políticas de la destrucción/Poéticas de la preservación: apuntes para uma lectura (eco)crítica del médio ambiente em América Latina. Rosario: Beatriz Viterbo, 2013. 
INGOLD, Tim. The perception of the environment: essays in livelihood, dwelling and skill. London, New York: Routledge, 2000.

Being alive: essays on movement, knowledge and description. London, New York: Routledge, 2011.

MERLEAU-PONTY, Maurice. Fenomenologia da percepção. 2. ed. São Paulo: Martins Fontes, 1999.

MOURÃO, Ada Raquel Teixeira, CAVALCANTE, Sylvia. Identidade de lugar. In: CAVAlCANTE, Sylvia, ELALI, Gleice A. (orgs.). Temas básicos em Psicologia Ambiental. Petrópolis: Vozes, 2011.

SAES, Sílvia Faustino de Assis. Percepção e imaginação. São Paulo: Martins Fontes, 2010.

SCHAMA, Simon. Paisagem e memória. São Paulo: Companhia das Letras, 1996.

SPELLER, Gerda M. A importância da vinculação aos lugares. In: SOCZKA, Luis (org.). Contextos Humanos e Psicologia Ambiental. Lisboa: Calouste Gulbenkian, 2005.

STEIL, Carlos Alberto, CARVALHO, Isabel Cristina de Moura. Introdução. In: STEIL, Carlos Alberto, CARVALHO, Isabel Cristina de Moura (orgs.). Cultura, percepção e ambiente: diálogos com Tim Ingold. São Paulo: Terceiro Nome, 2012.

TUAN, Yi-Fu. Topofilia: um estudo da percepção, atitudes e valores do meio ambiente. Londrina: Eduel, 2012.

Espaço e Lugar: a perspectiva da experiência. Londrina: Eduel, 2013.

WHITT, Laurie Anne, ROBERTS, Mere, NORMAN, Waerete, GRIEVES, Vicki. Perspectivas indígenas. In: JAMIESON, Dale (coord). Manual de Filosofia do Ambiente. Lisboa: Instituto Piaget, 2003. 